\title{
Spectrum of Alcoholic Liver Disease in Tribal Alcoholics of Chittagong Hill Tracts of Bangladesh
}

\author{
SARMISTHA IISWAS, ${ }^{1}$ SUJ AT PAUL, ${ }^{2}$ ABU SYEED, ${ }^{3}$ MD. SHAHRI AR MAHBUB, ${ }^{4}$ MOHAMMADASHI KIMRAN KHAN, ${ }^{5}$ RATAN \\ DAS GUPTA, ${ }^{1}$ MD. TITU MI AH, ${ }^{1} \mathrm{KFMAYAZ}^{1}{ }^{\text {APARNA DAS, }}{ }^{1}$ MD. BI LALALAM,${ }^{6}$ SYED GHULAM MOGNI MOWLA ${ }^{7}$
}

\begin{abstract}
:
Background: Alcohol is one of the most important causes of liver disease. In Bangladesh, alcoholism is not a usual practice among the general population as there are social and religious barriers against it. But in the Hill tracts, there is no social stigma in taking alcohol. Relatively little is known about this aspect in Bangladesh. This small-scale study was done to identify the spectrum of liver disease among tribal people.

Material and Methods: A descriptive, observational clinical study was conducted for a period of six months ( ( $^{\text {st }}$ July, 2007 to $3 \mathrm{I}^{\text {st }}$ December, 2007) on a series of 50 tribal alcoholic people, collected from General Hospital and the tribal community of Rangamati Hill District. Subjects were included from both the urban and rural area of different socioeconomic classes. History, meticulous clinical examination and investigations were done to detect the pattern of alcohol induced liver injury.

Results: Among the 50 cases, 47 patients were male and 3 were female cases. Both regular and irregular drinkers were included. The common symptoms of liver disease among tribal alcoholics were yellow coloration of sclera (24\%), nausea \& vomiting (20\%) and weight loss (I 4\%). The common findings were jaundice (24\%), anemia (20\%), ascites (10\%), edema (10\%) and hepatosplenomegaly (20\%). Liver function tests revealed only 17 patients had mild to severe form of hepatocellular damage. Hyperbilirubinemia was found in $34 \%$ participants. ASTIALT ratio more than 2 was found in $32 \%$ subjects. Ultrasonography was done in 46 out of 50 subjects: 29 cases reported as normal (63.04\%), fatty liver in 5 (10.87\%), acute hepatitis in 5 (10.87\%) and chronic liver disease in 7 (15.22\%) cases. Liver biopsy was possible in 4 suspected cases (clinically and biochemically) of alcoholic liver cirrhosis and histology supported the clinical diagnosis in these cases. So, alcohol induced liver damage was noticed only in 17 cases. Nearly two-thirds of the participants were free from any form of liver disease.
\end{abstract}

Conclusion: Despite the presence of risk factors for developing alcoholic liver disease, the prevalence was found to be low among the tribal alcoholic participants in this study.

Keyword: Alcoholic liver disease, alcoholic fatty liver, alcoholic hepatitis, alcoholic liver cirrhosis, tribal population, Bangladesh

\section{Introduction:}

Alcoholic liver injury occurs after prolonged heavy drinking, typically for at least 10 years and particularly among those who are physically dependent on alcohol. However, not everyone who drinks excess alcohol develops serious forms of alcoholic liver disease. It is likely that genetic factors determine this. ${ }^{1,2}$ The threshold for developing severe alcoholic liver disease in men is an intake of more than 60-80 $\mathrm{gm} /$ day of alcohol for 10 years, while women are at increased risk for developing similar degree of liver injury by consuming 20-40 gm/ day. ${ }^{2}$ In men, ingestion of 40-80gm/day of ethanol produces fatty liver; $80-160 \mathrm{gm} /$ day for $10-20$ years causes hepatitis or cirrhosis. Only 15\% of alcoholics develop alcoholic liver disease. $^{2}$

In Bangladesh, alcoholism is not a usual practice among the general population as there are social and religious barriers. But in the Hill tracts, the picture is different where there is no social stigma to take alcohol. Moreover, alcoholic drink is

1. Assistant Professor, Department of Medicine, Dhaka Medical College.

2. Assistant Professor, Department of Medicine, Chittagong Medical College.

3. Professor, Department of Medicine, Chittagong Medical College.

4. FCPS (Medicine) course student, Dhaka Medical College.

5. Post-graduate trainee, Department of Medicine, Dhaka Medical College

6. Associate Professor, Department of Medicine, Dhaka Medical College.

7. Assistant Professor, Department of Medicine, Shahid Sohrawardy Medical College.

Correspondence: Dr. Md. Shahriar Mahbub, Department of Medicine, Dhaka Medical College, Dhaka, Bangladesh. E-mail: shahriar04@yahoo.com 
encouraged in their social, familial and religious festivals. Most of the tribal people take alcohol- some are regular while others are irregular in this habit. Locally used alcoholic drinks in Chittagong Hill Tracts were named as 'Ekchuani' and 'Dochuani'. These contain 30-40\% alcohol in each $100 \mathrm{ml}$. If one takes one glass $(250 \mathrm{ml})$ of raw alcohol daily, (s)he consumes more than $60 \mathrm{gm}$ alcohol; that means he/she crosses the safety bar of alcohol consumption. So anyone who takes at least one glass of the locally made alcohol for at least 10 years, he/she is at risk of developing alcoholic liver disease. From the Hospital record of Rangamati General Hospital, it was found that from February 2004 to February 2007, total 8123 patients were admitted in Medicine ward. Among them, 123, 45 and 11 were cases of acute hepatitis, chronic liver diseases and hepatocellular carcinoma respectively and tribal patients with acute hepatitis, chronic liver disease and hepatocellular carcinoma were only 42, 45 and 5 respectively. It is interesting that although most of the tribal people were alcoholic, hepatic involvement was much less than expected. Despite the increased risk of liver disease in alcoholic tribal people, no study regarding this aspect has been done in Bangladesh. Rangamati Hill Tracts was an ideal field to work on the tribal alcoholics to obtain valuable data on the spectrum of liver disease among these people.

\section{Materials and Methods:}

It was an observational study done in Rangamati General Hospital (110 bed) and tribal community of Rangamati Hill District during the period of 6 months (from $1^{\text {st }}$ July 2007 to $31^{\text {st }}$ December, 2007). Fifty (50) tribal alcoholics were enrolled. The participants were followed up by using a specified protocol and evaluated under the following headings: history, clinical examination, laboratory investigations.

Inclusion criteria:

- Tribal people of $\geq 18$ years, having history of alcohol intake for at least 10 years

- Regular drinker, taking at least 60 grams of alcohol per day in male and 20 grams per day in case of female.

- Irregular drinker with drinking habit of at least 3 times per week and amount is 60 grams or more.

\section{Exclusion criteria:}

- Patients with known causes of hepatitis other than alcoholism (e.g. hepatitis B, hepatitis C)

- Intravenous drug users and
- $\quad$ Alcoholism with other co morbid disease like diabetes mellitus, Ischemic heart disease and COPD.

Informed consent was taken from all persons. Ethical approval for the study was provided by Ethical Research Committee.

\section{Results:}

A total of 50 tribal chronic alcoholics were included in this study. Out of 50 people, 47 were male and only 03 were female. Among the participants, majority (38 patients) were 40 years and above (Figure 1). Peoples belonging to high income group (>15000 taka/month) was 26\%, average income group 50\% and poor income group ( $<5000$ taka/month) was $24 \%$. Out of 50 alcoholic subjects, 27 peoples were from urban area, rest from rural areas of Rangamati Hill Tracts. Among the urban people, 20 were regular drinker and 07 took alcohol irregularly. The number of regular and irregular drinker in the rural people is 14 and 9 respectively. Among the regular ones (34), 20 had no evidence of hepatic injury, rest 14 showed mild to severe forms of liver damage. Among the irregular drinkers 13 revealed no hepatic insult. Rest three showed signs of chronic liver damage. Common symptoms among tribal alcoholics who developed liver disease were

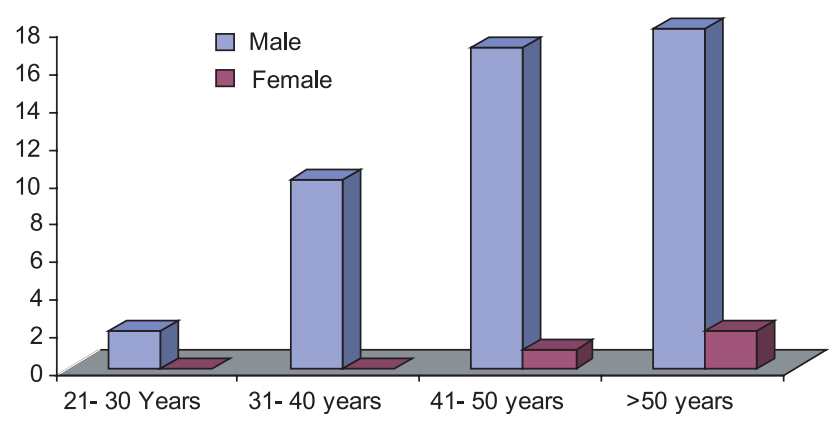

Fig-1: Age and sex distribution $(n=50)$

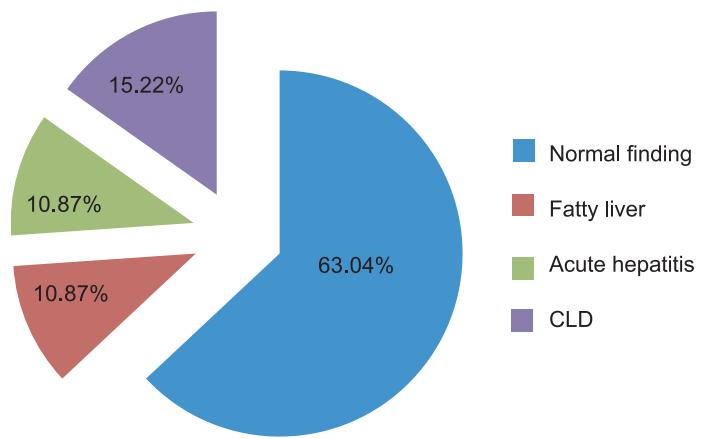

Fig-2: Ultrasonographic findings in tribal alcoholics $(n=46)$ 
jaundice (24\%), nausea, vomiting (20\%), weight loss (14\%) and the common signs were jaundice (24\%), anemia (20\%), hepatosplenomegaly (either or both) (20\%), edema (10\%), ascites (10\%) (Table-I). Hyperbilirubinaemia was found in $34 \%$ of cases and AST/ALT ratio was more than 2 in $32 \%$ of cases. GGT was done in 2 cases and value was raised in both them (Table-II). Ultrasonography was normal in 29 cases (63.04\%), fatty liver found in 05 (10.87\%), acute hepatitis in 05 (10.87\%), and CLD in 7 (15.22\%) (Figure-2). Sixty six percents of study population showed no evidence of hepatocellular injury; alcoholic fatty liver and acute hepatitis accounted in $10 \%$ for each and cirrhosis of liver was found in $14 \%$ (Table-III).

\section{Table-I}

Symptoms \& signs of liver disease among tribal alcoholics $(n=50)$

\begin{tabular}{|c|c|c|}
\hline Symptoms & Number & $(\%)$ \\
\hline Yellow coloration of sclera & 12 & 24 \\
\hline Nausea, vomiting & 10 & 20 \\
\hline Weight loss & 07 & 14 \\
\hline Abdominal lump & 06 & 12 \\
\hline Abdominal swelling & 05 & 10 \\
\hline Loss of body hair & 04 & 08 \\
\hline Ankle swelling & 05 & 10 \\
\hline Haematemesis and Malena & 04 & 08 \\
\hline \multicolumn{3}{|l|}{ Signs } \\
\hline Anemia & 10 & 20 \\
\hline Jaundice & 12 & 24 \\
\hline Leuconychia & 01 & 02 \\
\hline Clubbing & 04 & 08 \\
\hline Palmar erythema & 04 & 08 \\
\hline Wasting of thenar and hypothenar muscles & 06 & 12 \\
\hline Collateral vessels & 01 & 02 \\
\hline Gynaecomastia & 01 & 02 \\
\hline Testicular atrophy & 04 & 08 \\
\hline Bilateral parotid gland enlargement & 03 & 06 \\
\hline Ankle edema & 05 & 10 \\
\hline Ascites & 05 & 10 \\
\hline
\end{tabular}

Table-II

Values of Liver function tests

\begin{tabular}{|c|c|c|}
\hline Tests & $(n=50)$ & $(\%)$ \\
\hline \multicolumn{3}{|c|}{ Serum bilirubin (mg/dl) (R- 0.3 -10) } \\
\hline $0.12-1$ & 33 & 66 \\
\hline$>1-4$ & 10 & 20 \\
\hline$>4-10$ & 07 & 14 \\
\hline \multicolumn{3}{|l|}{ AST (IU/L) (R-25-387) } \\
\hline $10-45$ & 20 & 40 \\
\hline $46-150$ & 18 & 36 \\
\hline$>150$ & 12 & 24 \\
\hline \multicolumn{3}{|l|}{ Serum total protein $(n=14)$} \\
\hline Less than $3(\mathrm{gm} / \mathrm{dl})$ & 00 & 00 \\
\hline 3-5.9(gm/dl) & 03 & 21.40 \\
\hline 6 and above & 11 & 78.60 \\
\hline \multicolumn{3}{|l|}{ ALT(IU/L) } \\
\hline $10-50$ & 30 & 60 \\
\hline $51-100$ & 07 & 14 \\
\hline$>100-150$ & 07 & 14 \\
\hline$>150$ & 06 & 12 \\
\hline \multicolumn{3}{|l|}{ AST/ALT Ratio } \\
\hline$<1$ & 04 & 08 \\
\hline $1-2$ & 30 & 60 \\
\hline$>2$ & 16 & 32 \\
\hline Prothombin time $(n=08)$ & 06 & 7 \\
\hline Within 3 seconds of control5 & & \\
\hline $\begin{array}{l}\text { (12-15 seconds)More than } \\
3 \text { seconds) }\end{array}$ & 02 & 25 \\
\hline
\end{tabular}

Table-III

Hepatic findings among tribal alcoholics $(n=50)$

\begin{tabular}{lcc}
\hline Diagnosis & Number & Percentage \\
\hline No hepatic abnormality & 33 & $66 \%$ \\
Alcoholic fatty liver & 05 & $10 \%$ \\
Acute hepatitis & 05 & $10 \%$ \\
Cirrhosis & 07 & $14 \%$ \\
\hline
\end{tabular}

\section{Discussion}

This study was conducted on tribal alcoholics in a community setting and first of its kind in Bangladesh. The study found that although women were predominantly involved with the preparation of the famous tribal liquor 'Ekchuani' and 'Dochuani', very few consumed it. The amount consumed by the female was also much less than male. This is consistent with the observation found by Alexander Monto et al., S. Bellentini et al. and Stokkeland K et al. ${ }^{3-5}$ 
In the present series, the most common symptom of alcoholic liver disease was jaundice (24\%) along with nausea, vomiting, loss of body hair, abdominal lump. It is well known that alcoholic fatty liver usually remain asymptomatic. ${ }^{1,2,6,7}$ In acute alcoholic hepatitis, jaundice may be the only symptom and cirrhosis remain asymptomatic for prolonged period during which no sign and symptom appear. 1,2 Physiologists have called the liver 'servant of the body' because unlike other organs, it reveals its sufferings only when injuries are far advanced. Even in alcoholic cirrhosis, many cases (10$40 \%$ ) are discovered at laparotomy or autopsy. 1,7-9

Physical examination of the participants revealed that most of the alcoholics had no physical abnormality. In this series, commonest finding was jaundice (24\%). In alcoholic hepatitis, many patients may show no sign of liver damage. But it may be associated with wide range of clinical features like jaundice, abdominal tenderness, spider naevi etc. ${ }^{2}$ The reported incidence of clinical jaundice in chronic liver disease patients in Bangladesh ranges from 20-68.7\%1, 5,10 These variable incidence indicates that the variable percentage of decompensated patients belonging to the particular study. Jaundice in cirrhosis implies that liver cell destruction exceeds the capacity for regeneration and is always serious $1,2,7,9$ The deeper the jaundice, the greater the inadequacy of liver cell function. ${ }^{1,7}$ Anemia was detected in $20 \%$ cases. Anemia is possible in alcoholism due to malnutrition. ${ }^{2,6}$ Anemia in alcoholic cirrhosis is multifactorial and possible causes include nutritional deficiency, bleeding from gastrointestinal tract and increased splenic sequestration. 1, 2, 6

Other important signs demonstrated in this study were hepatomegaly, splenomegaly, hepatosplenomegaly, leuconychia, clubbing, palmar erythema and spider naevi. The incidence of these classic peripheral stigmata of cirrhosis is consistent with the findings of some other studies. ${ }^{11-13}$

In the present study, among the 50 tribal alcoholics, 5 had cirrhosis (10\%). Ascites along with jaundice were present in them. When ascites develops in a patient with chronic liver disease, the prognosis is always grave. ${ }^{14}$ Presence of ascites and jaundice together is also a poor prognostic sign. ${ }^{7,15}$

Liver function tests are the mirror on which hepatocellular functional status such as capacity, reserve, damage etc is reflected. In the present study, 33 cases had normal bilirubin level, 17 cases had hyperbilirubinaemia. Serum bilirubin can be normal in alcoholic fatty liver. ${ }^{1,2,5}$ The wide range of ALT (10-303) U/L and AST (25- 387) U/L indicates the variable spectrum of tribal alcoholic patients with different hepatocellular functional status. Serum AST is disproportionately elevated relative to ALT, which is a good indicator of alcoholic liver disease. Serum AST/ALT ratio is more than 1 in 60\% cases and more than 2 in 32\% in the present study.

Serum albumin level was found below normal (30 gm/L) in $18.18 \%$ of tribal alcoholic people. It is another indicator of hepatic dysfunction. ${ }^{1,2,5}$ Prothrombin time was done in eight indoor patients who showed signs of hepatocellular damage. Of them, 6 patients showed normal prothrombin time (within 15 seconds). It was prolonged in 2 patients. However, some authors like Dutta A.K, Rahman MS and Sabur MA found a higher percentage of patients having prolonged prothrombin time. ${ }^{16-18}$ As the investigation was done in few individuals, it may have underestimated the real extent of the abnormality.

Ultrasonography is an important noninvasive investigation in the evaluation of alcoholic liver disease. ${ }^{12,15}$ In cirrhosis, the edge of the liver may be irregular and the hepatic echo pattern may be coarse (increased irregular echogenicity). ${ }^{1,2}$ Fatty liver and hepatitis can also be suggested by ultrasonography. In the present study, ultrasonography was done in 46 persons. Of them, two thirds (29/46) revealed no evidence of liver injury. Fatty liver and acute hepatitis were found in 5 cases each. Cirrhosis was found in 7 participants. Liver biopsy was carried out only in 4 suspected patients and histology confirmed those as cirrhosis.

Finally, the physical signs, biochemical tests, ultrasonography and even liver biopsy report revealed that though all 50 subjects had the history of alcohol intake that crosses the safety bar to develop alcoholic liver disease two thirds of them were found asymptomatic. This finding is consistent with study done by Lelbech WK, Stokkeland K. and S. Bellentini etc. ${ }^{4,5,19}$ Rest of the 17 cases had different types of liver injury. It is really surprising that despite a high degree of alcohol consumption by the indigenous people which could lead to the development of cirrhosis of liver, the clinical findings and investigations revealed that most of them were not suffering from any type of liver damage.

In conclusion, it can be said that, the prevalence of alcoholic liver disease is not high in this study population. Rather the incidence is low. Further study in large scale of tribal alcoholics in three hill districts could shed clear light on this proposition and this will clearly define the actual situation.

\section{Conflict of Interest: None}

\section{References:}

1. Sherlock S, Dooley J. Diseases of the liver and billiary system, $9^{\text {th }}$ ed. Oxford: Blackwell Scientific Publications 1993: 649 
2. Brawnwald E, Hanser SI, Longo DL, Kasper DL, Jamson JL, Fauci AS, editors. Harrison's Principles of Internal Medicine $15^{\text {th }}$ ed New York: McGraw- Hill Inc. 2001: 1743

3. Alexender Monto, Keyur Patel, Alan Bostem, Stephen Pianko et al. Drinking habits as cofactors of risk for progression of Liver Disease. Hepatology 2004; 3:39

4. S. Bellentini, G Saccoccio, G. costa, et al. Drinking habits as cofactors of risk for alcohol induced liver damage. Gut 1997: 41: $845-850$

5. Stokkeland K, Hilm G, Spak F, et al. Different drinking patterns for women and men with alcohol dependence with or without alcoholic cirrhosis. Alcohol Alcohol 2008; 43(1): 39- 45

6. Colledge N, Walker B, Boon NA, eds. Davidson's Principles of Medicine, $20^{\text {th }}$ ed. London: Churchill Livingstone 2006

7. Cotran RS, Kumar V, Robbins SL. Robbin's Pathologic Basis of Disease, $4^{\text {th }}$ ed. Philadelphia: WB Saunders. 1989: 1519

8. Patek AJ Jr, Post J, Rantoff OD. The natural history of Lannec's cirrhosis of liver. Analysis of 386 cases. Medicine 1942; 21: 207- 13

9. Rocco VK, Ware AJ. Cirrhotic ascites. Ann Intern Med 1986; 105: 573- 85

10. Islam N, Khan M, Ahmed Z. Cirrhosis of liver. Bangladesh Med Res Counc Bull 1981; VII: 45- 51

11. Naveau S, Girraud V, Ganne N, et al. [Patients with alcoholic liver disease hospitalized in gastroenterology. A national multicenter study.] [French] Gastroenterol Clin Biol 2004
12. Leevy CM, Proper H, Sherlock S. Diseases of the liver and billiary tract standardization of nomenclature diagnostic criteria and diagnostic methodology. In: Fogarty International Center Proceedings No 22, DHEW publication no NIH76725, Washington DC: US Government printing office

13. Fifth Pan American Congress of Gastroenterology, Report of the Board for Classification and Nomenclature of Cirrhosis of the Liver. Gastroenterology. 1956;31:213-219

14. Robin E, Krus S, Popper H. Pathogenesis of postnecrotic cirrhosis in alcoholics, Arch Pathol 1962; 73: 288099

15. Galambose JT. Alcoholic liver disease fatty liver hepatitis and cirrhosis. In: Berk Je, editor. Bockus Gastroenterology $4^{\text {th }}$ ed Philadelphia: WB Saunders 1985: 3012- 48

16. Datta AK. Chronic Prenchymal liver disease clinical biochemical imaging and histopathological correlation (Dissertation). Dhaka: Bangladesh College of Physicians and Surgeons 1990: 132.

17. Rahman MS. Clinicopathological studies of cirrhosis of liver (Dissertation). Dhaka: Bangladesh College of Physicians and Surgeons, 1990: 117

18. Sabur MA. A clinical study of chronic liver disease (Dissertation). Dhaka: Bangladesh College of Physicians and Surgeons, 1988: 126

19. Lelbech WK. Cirrhosis in the alcoholics and its relation to the volume of alcohol abuse. Ann NY Acad Sci 1975: 73: 288- 99 